\title{
Genetic Diversity of the Sri Lanka Yellow Dwarf Coconut Form as Revealed by Microsatellite Markers
}

\author{
L.C.J. Kamaral, S.A.C.N. Perera* K.L.N.S. Perera ${ }^{1}$ and P.N. Dassanayaka ${ }^{2}$ \\ Genetics and Plant Breeding Division \\ Coconut Research Institute of Sri Lanka \\ Lunuwila 61150, Sri Lanka
}

\begin{abstract}
Sri Lanka Yellow Dwarf (SLYD) is an important coconut form as a parent in the national coconut breeding programme of Sri Lanka. Though dwarf coconuts are known to be purelines, SLYD displays uncharacteristic morphologies. The current research was conducted to characterize a sample of 15 SLYD individuals using 10 SSR marker loci to determine the genetic diversity within the form. One palm each of Sri Lanka Tall (SLT), Green Dwarf (GD) and Gon Thembili Tall (GT) were used as reference coconut forms. Genomic DNA was extracted and PCR amplification was performed followed by $6 \%$ denaturing polyacrylamide gel electrophoresis to visualize the bands. Genotypic data were analysed using PowerMarker software. All ten marker loci were polymorphic, and among them more informative microsatellite loci for the tested population were identified. A total of 34 alleles were scored in the 15 individuals of SLYD ranging from a minimum of two to a maximum of five and a total of 22 heterozygous loci were identified spreading across the ten marker loci. The results indicated the SLYD to share bands more frequently with tall coconut forms than GD. The dendrogram displayed three clusters of SLYD with one group including comparative form GD and another cluster including both SLT and GT. The observed heterozygosity, and genetic and allelic diversities exceed the levels that can be expected from dwarf coconut forms which are self-breeding purelines. It is recommended to purify SLYD coconut form to ensure genetic purity of SLYD parental palm pool in Sri Lanka.
\end{abstract}

Keywords: Coconut, genetic diversity, hybridization, SSR markers, yellow dwarf

\section{INTRODUCTION}

The coconut palm, Cocos nucifera, is a member of the family Arecaceae (palm family) and is the sole species of the genus Cocos. It is the most extensively grown plantation crop in Sri Lanka spanning over 394,000 ha in 2012 (Anonymous, 2012).

Every part of the coconut palm can be used in different ways. It is playing a significant role in the economic, cultural and social life of over 80 coconut growing countries in the world. Indonesia, the Philippines, India, Brazil and Sri Lanka are the major coconut growing countries. Sri Lanka is the $5^{\text {th }}$ largest coconut producer and has the highest per capita consumption of coconut in the world. The estimated per capita consumption of coconut in Sri Lanka is around 110 nuts/year (Anonymous, 2009), and $80 \%$ of the production is consumed domestically (Smith et al., 2009).

\footnotetext{
No.54, Kithulwatte Rd, Colombo 08, Sri Lanka

2 University of Sri Jayawardenepura, Gangodawila, Nugegoda, Sri Lanka

Corresponding author: chandrikaperera2003@yahoo.com
} 
Coconut germplasm in Sri Lanka is classified into three varieties, namely Tall (Typica), Dwarf (Nana) and Intermediate (Aurantiaca), based on their morphological traits and breeding behaviour (Liyanage, 1958). Tall coconuts are naturally cross pollinating and thus the populations show varying degrees of heterozygosity.

The dwarf coconuts are naturally self pollinating and as a result, those populations are predominantly purelines which display common morphological features such as, dwarf stature, slender trunks lacking a root-bole (enlarged base of the stem), drooping frond tips and smaller crowns. Dwarf forms also have short vegetative phase, small sized nuts having less copra content and bunches with high number of nuts compared to other varieties. These coconuts are not favoured as commercial cultivars, but are highly important as parents in genetically improved high yielding coconut hybrids. Dwarf coconut variety is divided into different forms based on the colour of the nuts/epicarp. In Sri Lanka, there are four such dwarf forms named Brown dwarf, Green dwarf, Red dwarf and Yellow dwarf. All these coconut forms display the above mentioned common traits except for Sri Lanka Yellow dwarf (SLYD). In SLYD some palms display morphologically non-uniform characteristics, for example tall stature, presence of a root-bole and larger crowns, which are quite uncommon features among dwarf coconut forms.

Sri Lanka Yellow Dwarf is an important parent in the national coconut breeding programme of the country. It is one of the dwarf coconut parents/accessions planted at Isolated Coconut Seed Garden (ISG) at Ambakelle and is used as the female parent palm pool to produce the improved hybrid CRIC65 (Yellow). This hybrid is a cross between SLYD x Sri Lanka Tall (SLT). The CRIC65 (Yellow) is an early flowering hybrid and a high nut producer with high kernel productivity. It is mass produced by directed natural pollination at the ISG at Ambakelle. Genetic uniformity of the parent palm pool is essential for uniform performance of the resultant hybrid. However, the SLYD population at ISG does not conform to this requirement.

Morphological characterization is the traditional method to analyze genetic diversity of coconut but this method is laborious, not very accurate and also time consuming. Therefore, different molecular methods have been developed using molecular markers such as, AFLP, RAPD, RFLP, SNP and microsatellites (SSR) to explore the genetic diversity of coconut.

Among the available molecular markers, microsatellites (SSR) markers are widely used and offer several advantages over other marker systems particularly because of their reproducibility, co-dominant nature (Vidigal and Rubiano, 2011). They have successfully been used to analyse genetic diversity of coconut in several studies (Martinez et al., 2010; Dassanayaka et al, 2003; Perera et al., 2001). Therefore, the present study was conducted to determine the genetic variation within SLYD parent palm pool at ISG, Ambakelle using ten SSR markers.

\section{METHODOLOGY}

Fifteen SLYD palms (Palm numbers: 11445, 11470, 11573, 11645, 11762, 11794, 11970, 11979, 11987, 12047, 12092, 12133, 12148, 12165, 12171) at ISG Ambakelle were randomly selected for the study. One palm each of Sri Lanka Tall (SLT), Green Dwarf (GD) and Gon Thembili (GT) were used as reference palms. 
Genomic DNA of 18 palms was extracted from leaf tissues using a modified CTAB DNA extraction method which is a modification of the protocol developed by Weising and Karl (1997) and Doyle and Doyle (1990).A total of ten microsatellite primer pairs consist of five CAC markers (Perera et al., 2003), three CNZ markers (Rivera et al., 1999), and two CnCir markers (Baudouin and Lebrun, 2002) were used for genotyping. Primer sequences, size of the amplicon and annealing temperatures for each marker pair are given in Table 1.

The PCR reaction mixture contained $4 \mu \mathrm{l}$ of template DNA, 1x Taq PCR green buffer containing $2 \mathrm{mM} \mathrm{MgCl}$, $1.25 \mathrm{U}$ of Taq DNA polymerase (Dream Taq- Fermentas), deoxynucleoside triphosphates $(0.35 \mathrm{mM}$ each; Geneshun Biotech) and $0.6 \mu \mathrm{M}$ concentration of the primer pair $\left(1^{\text {st }} \mathrm{BASE}\right)$ in final volume of $25 \mu \mathrm{l}$.

PCR programme consisted of 4 minutes initial denaturation at $94{ }^{\circ} \mathrm{C}$ followed by 35 cycles of 30 seconds at $94{ }^{\circ} \mathrm{C}, 30$ seconds at annealing temperature (Table 1) and one minute at $72{ }^{\circ} \mathrm{C}$, and final extension at $72{ }^{\circ} \mathrm{C}$ for 5 minutes using thermal cycler (Applied Biosystems). PCR product was subjected to $6 \%$ denaturing polyacrylamide gel electrophoresis followed by silver staining. Genotypic scores were allocated by visual detection. The software PowerMarker version 3.25 (Liu and Muse, 2005) was used to analyze the diversity using genotypic scores.

Table 1. Primer sequences, size of the PCR products and annealing temperatures of the microsatellite markers used for genotyping

\begin{tabular}{|c|c|c|c|c|}
\hline \multicolumn{2}{|c|}{ Oligo name } & \multirow{2}{*}{$\begin{array}{c}\text { Sequence } \\
\text { 5'-TGT ACA TGT TTT TTG CCC AA-3' }\end{array}$} & \multirow{2}{*}{$\begin{array}{r}\text { Size (bp) } \\
150-168\end{array}$} & \multirow{2}{*}{$\begin{array}{c}\begin{array}{c}\text { Annealing } \\
\text { Temperature } \\
{ }^{\circ} \mathrm{C}\end{array} \\
52\end{array}$} \\
\hline CAC 6 & $\mathrm{~F}$ & & & \\
\hline & $\mathrm{R}$ & 5'-CGA TGT AGC TAC CTT CCC C-3' & & \\
\hline \multirow[t]{2}{*}{ CAC 8} & $\mathrm{~F}$ & 5'-ATC ACC CCA ATA CAA GGA CA-3' & $188-210$ & 56 \\
\hline & $\mathrm{R}$ & 5'-AAT TCT ATG GTC CAC CCA CA-3' & & \\
\hline \multirow{2}{*}{ CAC 21} & $\mathrm{~F}$ & 5'-AAT TGT GTG ACA CGT AGC C-3' & 154 & 54 \\
\hline & $\mathrm{R}$ & $\begin{array}{l}\text { 5'-GCA TAA CTC TTT CAT AAG GGA3' } \\
\text { 5'-TGA AAA CAA AAG ATA GAT GTC }\end{array}$ & & \\
\hline \multirow[t]{2}{*}{ CAC 23} & $\mathrm{~F}$ & AG-3' & 192 & 56 \\
\hline & $\mathrm{R}$ & 5'-GAA GAT GCT TTG ATA TGG AAC-3' & & \\
\hline \multirow{2}{*}{ CAC 65} & $\mathrm{~F}$ & 5'-GAA AAG GAT GTA ATA AGC TGG-3' & 150 & 54 \\
\hline & $\mathrm{R}$ & 5'-TTT GTC CCC AAA TAT AGG TAG-3' & & \\
\hline \multirow[t]{2}{*}{ CNZ 6} & $\mathrm{~F}$ & 5'-ATA CTC ATC ATC ATA CGA CGC-3' & 85 & 52 \\
\hline & $\mathrm{R}$ & 5'-CTC CCA CAA AAT CAT GTT ATT-3' & & \\
\hline \multirow[t]{2}{*}{ CNZ 44} & $\mathrm{~F}$ & 5'-CAT CAG TTC CAC TCT CAT TTC-3' & 165 & 52 \\
\hline & $\mathrm{R}$ & 5'-CAA CAA AAG ACA TAG GTG GTC-3' & & \\
\hline \multirow[t]{2}{*}{ CNZ 46} & $\mathrm{~F}$ & 5'-TTG GTT AGT ATA GCC ATG CAT-3' & 116 & 56 \\
\hline & $\mathrm{R}$ & 5'-AAC CAT TTG TAG TAT ACC CCC-3' & & \\
\hline \multirow[t]{2}{*}{ CnCir 1} & $\mathrm{~F}$ & 5’-TTG GTC TAT TGC ATG TTC-3’' & 150 & 44 \\
\hline & $\mathrm{R}$ & 5'-TGG CAT TGA GAG GGT-3' & & \\
\hline \multicolumn{2}{|c|}{ CnCir A 4 F } & 5'-GTT GGT TAC TGG AAA TCT T-3' & $196-204$ & 50 \\
\hline & $\mathrm{R}$ & 5'-CAT GAC ATA CGG ACT AGC-3' & & \\
\hline
\end{tabular}




\section{RESULTS AND DISCUSSION}

The total of 18 palms used in this study comprised of 15 SLYD, and three reference palms (GD, SLT and GT). GD palm was selected as a reference variety for dwarf coconuts where SLT and GT palms represented common tall and tall coconuts with yellow colour nuts, respectively. The gel images (Figure 1 and Figure 2) display the polymorphism of two loci ranging from two to five alleles per locus. The numbers of heterozygous individuals at each marker locus and the respective scores are presented in Table 2.

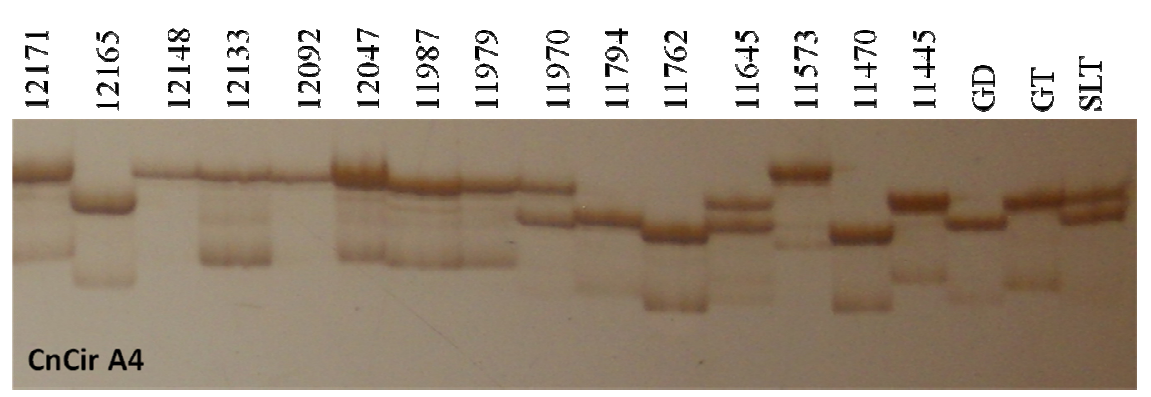

Fig. 1. Polyacrylamide gel image of marker locus CnCir A4

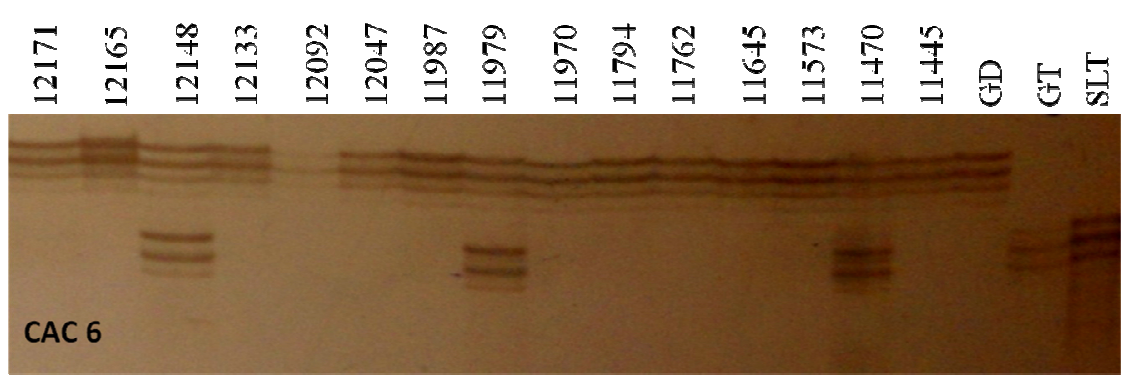

Fig. 2. Polyacrylamide gel image of marker locus CAC 6 
Table 2. Alleles scored and levels of heterozygosity of ten marker loci (Letters within parenthesis are the notations given for eachallele).

\begin{tabular}{|c|c|c|c|c|c|c|c|c|}
\hline \multirow{2}{*}{$\begin{array}{l}\text { Marker } \\
\text { locus }\end{array}$} & \multicolumn{2}{|l|}{ SLYD } & \multicolumn{2}{|c|}{ GD } & \multicolumn{2}{|c|}{ SLT } & \multicolumn{2}{|c|}{ GT } \\
\hline & NA* & $\mathbf{H} / \mathbf{T I} \mathbf{I}^{* *}$ & NA* & H/TI** & NA* & H/TI** & NA* & $\mathbf{H} / \mathbf{T I}^{* *}$ \\
\hline CAC6 & $5(\mathrm{C} 1, \mathrm{C} 2, \mathrm{C} 3, \mathrm{C} 4, \mathrm{C} 5)$ & $5 / 15$ & $1(\mathrm{C} 1)$ & $0 / 1$ & 1 (C6) & $0 / 1$ & 1 (C6) & $0 / 1$ \\
\hline CAC8 & $3(\mathrm{D} 1, \mathrm{D} 2, \mathrm{D} 3)$ & $3 / 15$ & 1 (D1) & $0 / 1$ & 1 (D3) & $0 / 1$ & 1 (D3) & $0 / 1$ \\
\hline CAC21 & $2(\mathrm{E} 1, \mathrm{E} 2)$ & $1 / 15$ & 1 (E1) & $0 / 1$ & $1(\mathrm{E} 1)$ & $0 / 1$ & $2(\mathrm{E} 1, \mathrm{E} 2)$ & $1 / 1$ \\
\hline CAC23 & $2(\mathrm{~F} 1, \mathrm{~F} 2)$ & $2 / 15$ & $1(\mathrm{~F} 1)$ & $0 / 1$ & $1(\mathrm{~F} 2)$ & $0 / 1$ & $1(\mathrm{~F} 2)$ & $0 / 1$ \\
\hline CAC65 & $5(\mathrm{~A} 1, \mathrm{~A} 2, \mathrm{~A} 3, \mathrm{~A} 4$ & $5 / 15$ & 1 (A1) & $0 / 1$ & - & - & $1(\mathrm{~A} 2)$ & $0 / 1$ \\
\hline CNZ6 & A5) & $2 / 15$ & $1(\mathrm{~J} 3)$ & $0 / 1$ & $1(\mathrm{~J} 1)$ & $0 / 1$ & $1(\mathrm{~J} 1)$ & $0 / 1$ \\
\hline CNZ44 & $3(\mathrm{~J} 2, \mathrm{~J} 3, \mathrm{~J} 4)$ & $1 / 15$ & 1 (B2) & $0 / 1$ & 1 (B1) & $0 / 1$ & 1 (B1) & $0 / 1$ \\
\hline CNZ46 & 3 (B2, B3, B4) & $1 / 15$ & 1 (G1) & $0 / 1$ & $1(\mathrm{G} 2)$ & $0 / 1$ & $1(\mathrm{G} 2)$ & $0 / 1$ \\
\hline CnCir1 & $3(\mathrm{G} 1, \mathrm{G} 2, \mathrm{G} 3)$ & $1 / 15$ & $1(\mathrm{H} 2)$ & $0 / 1$ & $1(\mathrm{H} 1)$ & $0 / 1$ & $1(\mathrm{H} 1)$ & $0 / 1$ \\
\hline $\mathrm{CnCirA} 4$ & $5(\mathrm{H} 1, \mathrm{H} 2, \mathrm{H} 3, \mathrm{H} 4, \mathrm{H} 5)$ & $1 / 15$ & $1(\mathrm{I} 2)$ & $0 / 1$ & $2(\mathrm{I} 2, \mathrm{I} 3)$ & $1 / 1$ & 1 (I3) & $0 / 1$ \\
\hline Total & $\begin{array}{l}3(\mathrm{I} 1, \mathrm{I} 2, \mathrm{I} 3) \\
\mathbf{3 4}\end{array}$ & $22 / 150$ & 10 & $0 / 10$ & 10 & $1 / 9$ & 11 & $1 / 10$ \\
\hline
\end{tabular}

$*$ NA $=$ No of alleles

** H/TI indicates the levels of heterozygosity observed for each coconut form at the tested marker loci and calculated by Number of heterozygous loci $(\mathrm{H})$ / Total number of diploid loci scored in the particular variety (TI))

A total of 34 alleles were scored in the 15 individuals of SLYD at the 10 marker loci tested. The results revealed a total of 22 heterozygous loci spreading in SLYD, across all the markers. The dwarf coconuts are naturally self-pollinating homozygous purelines, and it was confirmed in GD which recorded 100\% homozygosity in the 10 SSR loci tested. The two tall coconut forms, SLT and GT recorded 10 and 11 alleles, respectively and each possessed only one heterozygous locus out of the 10 loci tested. The presence of heterozygotes at such a high rate in SLYD is uncharacteristic and does not conform to the common genetics of dwarf coconuts.

As presented in Table 2, all the alleles scored in GD palm were shared by SLYD. The alleles scored in SLT and GT palms also were shared by SLYD except for CAC6, CNZ6 and CNZ44 loci where, SLT and GT recorded three unique alleles. However, out of the total of 12 alleles scored in the tall palms (SLT and GT) only two were common with GD and they were also at heterozygous stage in the two tall forms. Thus, the results indicate that SLYD as a population share common alleles with tall coconuts more frequently, while that of the comparative dwarf form GD is infrequent and less common.

\section{Summary statistics of genotypic data}

Summary statistics of the genotypic data is reported in Table 3 for the 15 palms of the SLYD coconut form. All ten pairs of coconut specific SSR markers showed polymorphism. The number of alleles scored ranged from a minimum of two to a maximum of five alleles recording a total of 34 alleles with a mean value of 3.4. The Microsatellite locus CAC65 formed nine different genotypes within the 15 palms recording a high genetic diversity at that marker locus. The average number of genotypes formed at the 10 marker loci of the 15 individuals was five. In addition, as given in Table 3, gene diversity and heterozygosity values also were higher than those that would expect in a genetically uniform dwarf coconut form. 
Table 3. Summary statistics of genotypic data of SLYD (PIC= polymorphic information content).

\begin{tabular}{lcccccc}
\hline Marker & $\begin{array}{l}\text { Number } \\
\text { of alleles }\end{array}$ & $\begin{array}{l}\text { Major } \\
\text { Allele } \\
\text { Frequency }\end{array}$ & $\begin{array}{l}\text { Number of } \\
\text { Genotypes }\end{array}$ & $\begin{array}{l}\text { Gene } \\
\text { Diversity }\end{array}$ & Heterozygosity & PIC \\
\hline CAC65 & 5 & 0.4667 & 9 & 0.6867 & 0.3333 & 0.6412 \\
CNZ44 & 3 & 0.7667 & 4 & 0.3844 & 0.0667 & 0.3514 \\
CAC6 & 5 & 0.7667 & 5 & 0.3956 & 0.3333 & 0.3758 \\
CAC8 & 3 & 0.8000 & 5 & 0.3378 & 0.2000 & 0.3092 \\
CAC21 & 2 & 0.9667 & 2 & 0.0644 & 0.0667 & 0.0624 \\
CAC23 & 2 & 0.8667 & 3 & 0.2311 & 0.1333 & 0.2044 \\
CNZ46 & 3 & 0.8333 & 3 & 0.2867 & 0.0667 & 0.2604 \\
CnCir1 & 5 & 0.7333 & 5 & 0.4422 & 0.0667 & 0.4205 \\
CncirA4 & 3 & 0.8333 & 4 & 0.2911 & 0.0667 & 0.2710 \\
CNZ6 & 3 & 0.5667 & 5 & 0.6022 & 0.1333 & 0.5504 \\
Mean & 3.4 & 0.7600 & 5 & 0.3722 & 0.1467 & 0.3447 \\
\hline
\end{tabular}

\section{Phenetic tree}

The phenetic tree drawn based on neighbour joining method and showing the genetic relationships among SLYD, SLT, GD and GT is presented in Figure 3.

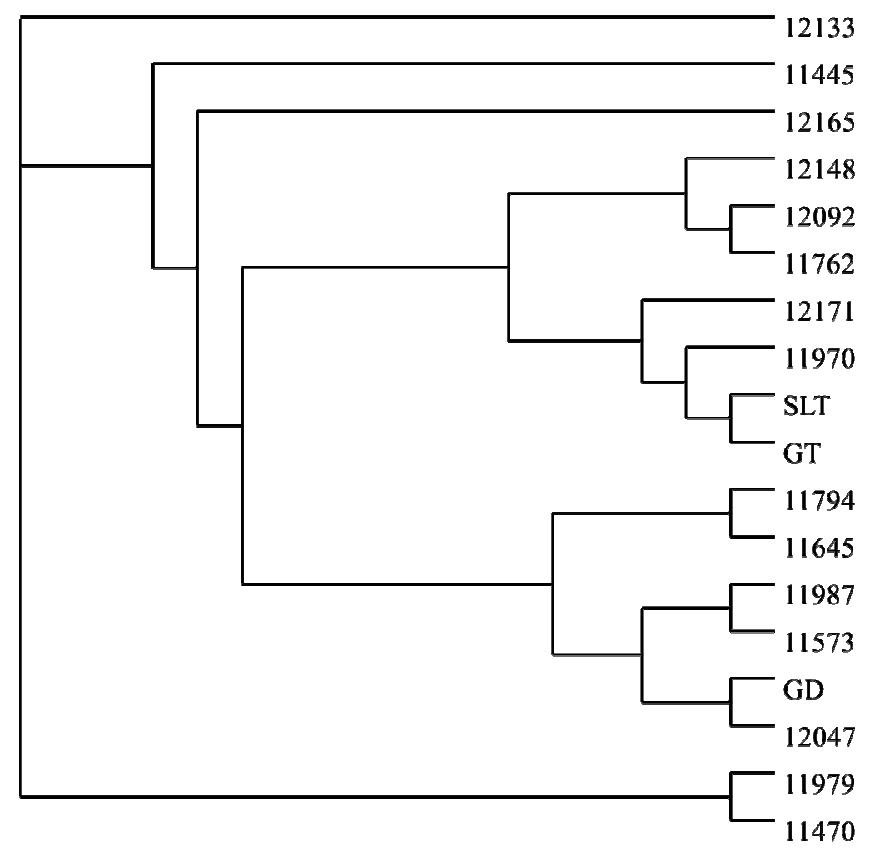

Fig. 3. Neighbour Joining Tree showing clustering pattern between SLYD, GD, SLT and GT individuals 
The dendrogm displays three clear clusters while a few SLYD palms (12133, 11445 and 12165 separated out from the three main clusters. The first main cluster included five SLYD (12148, 12092, 11762, 12171 and 11970) individuals along with SLT and GT. The second main cluster included five SLYD palms (11794, 11645, 11573, 11987 and 12047) along with GD with one SLYD individual (12047) being similar to GD. The third cluster was small including only two SLYD palms. These results indicate high genetic diversity within the SLYD population represented in different clusters along with other coconut form.

Tall and Intermediate coconut varieties have been reported to have higher variation than Dwarf varieties (Perera et al., 2000). As pointed out earlier the dwarf palms are reported to be homozygous purelines which is supported by the results reported in the present study in relation to GD. However, the finding clearly indicated that the SLYD population does not conform to the previous knowledge of low genetic diversity within the dwarf coconut. In contrast, SLYD individuals included in the current study reported high allelic and genetic diversity. Dwarf coconuts have been originated from tall coconuts (Perera et al., 2003) and as such the dwarf coconuts represent a subset of alleles from the tall coconuts. In the current study SLYD alleles were common with tall coconuts SLT and GT indicating that the SLYD coconuts areto have mixed genotypes. A preliminary study done by Kamaral et al. (2008) also provided both molecular and morphological evidence for the genetic non-uniformity of the SLYD population.

Out of the tested microsatellite markers, CAC65 was identified as the most informative for the SLYD coconut form. The results also indicated that the markers CAC6 and CNZ6 to be sufficiently informative to separate SLYD palms from SLT and GT coconut forms.

Any genetic difference within the parental populations of hybrid coconuts would result in non-uniformity of the resultant hybrids. The genetic variation so far observed in the Sri Lankan Yellow Dwarf populations may directly and adversely affect on the uniformity of the hybrid coconut planting material. Therefore, it is recommended to purify SLYD population to ensure genetic purity of SLYD parental palm pool.

\section{CONCLUSIONS}

There is a high genetic diversity exists within Sri Lanka Yellow Dwarf coconut form. The observed genetic and allelic diversity of Sri Lanka Yellow Dwarf coconut form exceeds the levels that can be expected from dwarf coconuts which are self breeding purelines. Therefore, there is an urgent need to purify the Sri Lanka Yellow Dwarf coconut form to be used in the coconut breeding programme.

\section{ACKNOWLEDGMENTS}

Authors wish to acknowledge National Research Council Sri Lanka for the financial support under the grant No. 11-042. The authors also wish to thank Mrs. W. B. S. Fernando, Genetics and Plant Breeding Division, Coconut Research Institute, Lunuwila and all the staff members of paternity testing division, Genetech, Kithulawatte road, Colombo 8 for assistance in technical matters. 


\section{REFERENCES}

Anonymous (2009). Annual Report of the Central Bank of Sri Lanka.

Anonymous (2012). Annual Report of the Central Bank of Sri Lanka.

Baudouin, L. and Lebrun, P. (2002). The development of a microsatellite kit and dedicated sofware for use with coconuts. Burotrop Bull. 17, 16 - 20.

Dassanayaka, P.N., Everard, J.M.D.T., Karunanayake, E.H. and Nandadasa, H.G. (2003). Characterization of coconut germplasm by microsatellite markers, Tropical Agricultural Research.15, 51 - 61.

Doyle, J.J. and Doyle, J.L. (1990). Isolation of plant DNA from fresh tissues. Focus 12, 13 15.

Kamaral, L.C.J., Perera, S.A.C.N. and Attanayake, D.P.S.T.G. (2008). Molecular Evaluation of different morphotypes of the coconut variety Sri Lanka Yellow Dwarf. Proceedings of the $8^{\text {th }}$ Agricultural Research Symposium. Wayamba University of Sri Lanka. 149 - 153.

Liu, K. and Muse, S.V. (2005). PowerMarker; Integrated analysis environment for genetic marker data. Bioinformatics. 21(9), 2128 - 2129.

Liyanage, D.V. (1958). Varieties and forms of the coconut palm grown in Ceylon. Ceylon coconut quarterly. 9, 1 - 10 .

Martinez, R.T., Baudouin, L., Berger, A. and Dollet, M. (2010). Characterization of genetic diversity of the tall Coconut (Cocos nucifera L.) in the Dominican Republic using microsatellite markers. Tree Genetics \& Genomes. 6, 73 - 81

Perera, L., Russell, J.R., Provan, J. and Powell, W. (2000). Use of microsatellite DNA markers to investigate the level of genetic diversity and population genetic structure of coconut (Cocos nucifera L.). Genome. 43, 15 - 21.

Perera, L., Russell, J.R., Provan, J., and Powell, W. (2001) Levels and distribution of genetic diversity of coconut (Cocos nucifera L., var. Typica form typica) from Sri Lanka assessed by microsatellite markers. Euphytica. 122, 381 - 389.

Perera, L., Russell, J.R., Provan, J. and Powell, W. (2003). Studying genetic relationships among coconut varieties/populations using microsatellite markers. Euphytica. 132, 121 128.

Rivera, R., Edwards, K.J., Barker, J.H.A., Arnold, G.M., Ayad, G., Hodgkin, T. and Karp, A. (1999). Isolation and characterization of polymorphic microsatellites in Cocos nucifera L.

Genome. 42, 668 - 675.

Smith, N., My Ha, N., Cuong, V.K., Dong, H.T.T., Son, N.T., Baulch, B. and Thuy, N.T.L. (2009) Coconuts in the Mekong Delta. (Accessed on 19.4.2013) Available at http://prosperityinitiative.org/images/stories/Coconuts_in_the_Mekong_Delta.pdf. 
Vidigal, M.C.G. and Rubiano, L.B. (2011). Development and application of microsatellites in plant breeding. Crop Breeding and Applied Biotechnology Sl. 66 - 72.

Weising, K. and Kahl, G. (1997). Hybridization-based microsatellite fingerprinting of plants and fungi In DNA markers; protocols, applications and overviews. Casteno-Anolles $G$ and Gresshoff PM (eds). Wiley-VCH (pub), 27 - 53. 